\title{
BLOCKCHAIN MARKET: REGULATORY CONCERNS ARISING FROM THE 'DIEM' EXAMPLE IN THE FIELD OF FREE COMPETITION ${ }^{1}$
}

\author{
Eleni Katopodi, LL.M PhD Candidate (University of Augsburg) \\ Research Associate, Technical University of Munich (TUM) \\ Arcisstraße 21, 80333 München, Germany \\ elenekatopode@gmail.com
}

\begin{abstract}
The purpose of this paper is to shed light on competition law issues arising from the extensive use of the blockchain technology. By using the example of the Diem, which has also aroused the interest of the European regulators, the author will try to illustrate the issues that the competent competition authorities will immediately have to deal with. These preliminary questions relate mainly to the re-definition of the concept of an 'undertaking' under the new circumstances and the attempt to define the relevant market on the basis of the existing theories. Indeed, legal scientists and economists have succeeded in highlighting the predominant theories for defining the relevant market in the blockchain environment. This study aims to support this vivid theoretical dialogue by suggesting an holistic theory which compromises all those previously expressed elements. In conclusion, this paper intends to investigate whether these new circumstances are endangering the very existence of competition law itself. The latter, in order to continue to fulfil its aim effectively, is probably very close to radical reforms, even in its most fundamental pillars.
\end{abstract}

Keywords: Antitrust, Blockchain, Competition Law, Cryptocurrencies, Diem, Libra, Facebook, Relevant Market

\section{INTRODUCTION}

Not too long after Facebook announced the introduction of the brand-new cryptocurrency 'Libra', the European institutions realized it was high time for regulatory intervention. As usual, competition law issues came to the forefront and the

\footnotetext{
1 The paper has already been presented in the framework of the International (Online) Jean Monnet Module Conference on EU and Comparative Competition Law Issues in May 13, 2021.
} 
competent authorities started to reconsider the possibility of regulating. More precisely, what previously was considered as precautious and far-fetched regulation suddenly turned into a matter of actual so-called 'urgent regulation'. In December 2020, the Libra Association was renamed Diem Association as an effort to prove the 'institutional independence' of the company and answer the regulatory concerns of the European Commission. Nonetheless, the road towards regulation was left wide open and all concerned European institutions were pretty convinced that changes and legislative production were admittedly inevitable.

However, before even attempting to urgently regulate the market, it is essential that both the regulatory authorities and competition lawyers understood the very special characteristics of this leading edge of technology and the way that the market of blockchains and cryptos is actually structured. Through the whole process of understanding, one could be able to navigate beyond the various types of cryptocurrencies and realize which is the role that Diem came to play into this market. Without the appropriate understanding of the technology, it is really difficult to decide if the whole structure would result in being rather problematic in respect to competition law. The bare fact that there is a possibility of straight opposition to the rational of consumers' welfare, if the playing field did not provide for the necessary rules for such an initiative, should not be taken for granted without any further examination. To this end, many experts tried to offer potential analyses and feedback in order to facilitate the corresponding activities of the responsible authorities and the courts. Yet, this rhetoric remains without essential sense, if ever not used and applied practically.

First of all, the main aim of this contribution is to elaborate on those fundamental elements that the interpreter should take into account in order to effectively apply antitrust legislation on blockchains. In particular, it aims to enhance the existing literature by adding and underlining those most crucial questions regarding the 'definition of the relevant market' for blockchains as well as the notion of the 'firm' itself. Absolute overregulation and application of traditional rules without a whole understanding of the issues would result in the suppression of a highly innovative technology. It is natural that one cannot reject the notion of the technology itself due to the inefficiencies and inadequacies of the present legal system and the lack of information.

Secondly, prompted by recent example, this paper will analyse Facebook's business plan behind Diem. It will highlight that blockchain technology can actually be useful in protecting consumer data, as well. The encrypted form of blockchains could be extensively used to authenticate users through online platforms instead of the use of the Facebook account. The latter requires much more data and is arguably more unsafe. 
As a final remark, the author shall conclude to a brief opinion on the relation between antitrust and blockchain and answer to the theories that would not stop emphasizing that probably the existence of blockchain would mean the death of antitrust. To this substantial question, the necessity of regulatory intervention to the aim of further protection of antitrust principles and market conditions as a whole is stressed.

\section{OVERVIEW OF THE BLOCKCHAIN STRUCTURE}

\subsection{The Blockchain mechanism in general}

The main feature of the blockchain technology is its decentralized nature (namely without a central repository), which ensures the maximum possible data security for users (distributed ledger technology). In particular, the complete absence of intermediaries and the cryptographic method favorize the anonymity and safety of transactions ${ }^{2}$. As a result, this mechanism is basically based on the building of trust among users. This is exactly the heart and flesh of this new technology and where its novelty lies on the whole.

Practically speaking, blockchain as it is mostly being used today, is nothing more than an advancing list of encrypted records, namely the blocks (data packages), which store multiple transactions $s^{3}$. The overall structure of the most common blockchains is based on the existence and interaction of three actors: the creators of the software, the miners ${ }^{4}$ and the users of the blockchain.

Existing blockchain mechanisms are divided into public (usually 'permissionless') and private (usually 'permissioned's). On the one hand, the public blockchain is accessible to all, more transparent and fully decentralized, in the sense that there is no distinct entity to exercise substantial control. It is called 'permissionless' in the sense that anyone with an Internet connection can freely access them, obtain an account and conclude contracts without needing a special permission by an authority. ${ }^{6}$ As permissionless blockchains are broadly accessible, there are people that will try to publish blocks in a way to distort the functioning of the system. For the prevention of these behaviors, blockchain networks often use a special

2 Nofer N., Gomber P., Hinz Ol., Schiereck D., Blockchain, Business and Information Systems Engineering, Vol. 59, No. 3, 2017, pp. 183.

3 Nofer et al, ibid.

4 In some blockchain ecosystems, miners do not exist at all.

5 The term 'usually' is used because private blockchains are typically permissioned, but they can also be organised differently. See supra note 2.

$6 \quad$ Yaga D., Mell P., Roby N. and Scarfone K., Blockchain technology overview, 2018, pp. 5 [https://arxiv. org/ftp/arxiv/papers/1906/1906.11078.pdf] Accessed 30.06.2021. 
multilateral 'consensus mechanism' which demands a certain process on behalf of the operators of the blockchain so that the blocks are finally published. ${ }^{7}$ In this context, each user can keep a copy of the blockchain on their personal computer and ensure access and ability to trade within the platform through the providing of two personal keys, one public and one private. The transactions executed are added as data units at the end of an infinite transaction chain in encrypted form. By approving the transaction and creating the block, it becomes immutable.

The phenomenon, according which transactions are visible to an infinite number of people is called 'visibility effect' and constitutes the basic trait of public blockchains. ${ }^{8}$ What is never revealed is the purpose and the subjects of the transaction ('opacity effect') and that is mainly the reason why blockchain is the most preferable means of transaction for prohibited activities. Before entering, each user should accept the blockchain protocol, which is mainly the rules governing the blockchain and cannot be changed unless all users commit to that.

In contrast, access to the permissioned (private) blockchain cannot be authorized unless someone is invited by a certain authority (the network administrators). They are based on a different policy and the transactions are not visible to everyone. Changes into the consensus mechanism can take place if the creators and the network administrators vote accordingly. In the permissioned ecosystems, the relations among the members of the blockchain tend to be based in mutual trust, as each user is authorized to publish blocks and since this authorization can be revoked in cases of misconduct. ${ }^{9}$ Private blockchains are more likely to cause more problems of an anticompetitive nature than permissionless blockchains, as the control over the permissioned blockchain is more evident and intense. In this framework, the users work together to achieve the business goal and maintain stability into the blockchain system. However, this does not exclude in any case the possibility of anticompetitive conduct into the system of a permissionless blockchain, as well. ${ }^{10}$

\subsection{The structure of Diem}

Recently Facebook introduced a new cryptocurrency, Diem, to enhance its existing portfolio of information and to provide significant economic data. Diem will

7 Ibid.

8 However visible to everyone does not necessarily mean 'permissionless': the number of users allowing to write into the blockchain each time can still be limited (or just one person), meaning it would be permissioned.

$9 \quad$ Yaga D. et al, ibid, 6.

10 Indeed, this would result in an actual more severe problem for the Competition authorities. 
be able to be 'stored' in the wallet run by a company called Novi (formerly Calibra), in which Facebook participates as the main stakeholder and wallet possessor.

Diem belongs to the stablecoins and is based on a permissioned and private blockchain. That was exactly what drew the European Commission's attention in $2019,{ }^{11}$ because in contrast to all the other cryptocurrencies of the market which operate on the basis of a permissionless system, ${ }^{12}$ Diem will initially have an entry control phase. ${ }^{13}$ In the business plan of the initial company, it was clearly stated that after an undefined period of time, Diem will switch into a permissionless system. ${ }^{14}$ The undefined element leaves adequate space for doubts on behalf of the responsible institutions both in the European Union and in the US. ${ }^{15}$

In addition, a permissioned blockchain cannot be as decentralized as the permissionless ones. As the validators belong to a certain closed association which governs the whole system cannot help but be fairly centralized. ${ }^{16}$ This seems more similar to a corporate database than a cryptocurrency, such as Bitcoin, which is mainly in opposition to the main idea of distributed ledger technology.

\section{REGULATORY CONCERNS}

There is a strong debate on the application of the traditional dogmas of competition law in modern digital markets. In the case of blockchain technology (especially cryptocurrencies), the situation is made far more difficult and challenges arise given their decentralized and horizontal nature. In these markets, the roles of its classical players change and move away from the classic rules and theories, generally applied to centralized platforms. As a classical example, the collusive behavior among players can be stressed. The latter -unlike to all other situations- is to be considered as a necessary condition to the maximization of the value of the cryptocurrencies. For example, the Diem protocol seems to favorize such collusive

11 Beyoud and White, Facebook's Libra Currency gets European Union Antitrust Scrutiny, 2019, [https:// www.bloomberg.com/news/articles/2019-08-20/facebook-s-libra-currency-gets-european-union-antitrust-scrutiny] Accessed 08.02.2021.

12 The most prominent example being Bitcoin.

13 See GKToday [https://www.gktoday.in/current-affairs/what-is-diem/] Accessed 08.02.2021.

14 Schrepel T., Libra: A Concentrate of Blockchain Antitrust, Michigan Law review Online, Vol. 118, 2020, pp. 163; Diem White Paper [https://www.diem.com/en-us/wp-content/uploads/2019/06/LibraWhitePaper_en_US.pdf] Accessed 07.02.2021.

15 NYS Attorney General, Attorney General James Gives Update on Facebook Antitrust Investigation, 2019 [https://ag.ny.gov/press-release/2019/attorney-general-james-gives-update-facebook-antitrust-investigation] Accessed 08.02.2021.

16 See BinanceAcademy, What is Facebook Libra (Diem)?, 2021, [https://academy.binance.com/en/articles/what-is-facebook-libra-diem] Accessed 08.02.2021. 
behavior by enhancing the founders to coordinate the capture of fees, excluding others from the process. This cooperation of the factors within a market inevitably leads to market sharing. ${ }^{17}$

The nature of the blockchain technology itself poses a great many challenges in the field of competition law. Pursuant to author's opinion, the distinctions between the mechanisms of public and private blockchain should impose a differentiation at a level of legislative treatment. Especially, the expansion and the need for a dynamic interpretation of important components of competition law should be come into consideration for the interpreters. Without the existence of appropriate methodological tools such as the aforementioned, the achievement of actually diagnosing infringements of competition law cannot but simply be a typolatric reproduction of rules and dogmas, without any significant impact on established real situations.

In particular, for the purposes of applying the provisions of Article $102 \mathrm{TFEU}$ as well as the merger control regulation, the interpreter is confronted with a fundamental question. And this question arises even before attempting to identify potential forms of abuse in each particular case and in order to abstain from obvious errors in their analysis: 'Is the existence of a dominant market position in this case established?'. The answer may be particularly challenging even for the traditional markets despite the existence of all those available means of the theory of economic analysis throughout the years. Besides, if one gets deeper into the mechanism of blockchain, they realize that the difficulties arising are many more compared with conventional markets. In this context, 'the definition of relevant market' in order to establish a dominant position in private and public blockchain systems is an apple of controversy between analysts. Having done that is a good first step not only to define the market power of its firm competing in the market but also to define the actual persons -natural or legal- that bear the liability for the company's anticompetitive conduct.

\subsection{The definition of relevant market}

Examining the existence of a dominant position in a digital market, even when the firms involved function over an exclusive centralized system, should not solely focus on the price factor of competition ${ }^{18}$, as in most of those markets companies compete at a "zero-price" level (e.g., Google, Facebook, Instagram, Twitter). That

\footnotetext{
$17 \quad$ Schrepel T., op. cit., note 7, 164.

18 OECD, Abuse of Dominance in Digital Markets, 2020, [http://www.oecd.org/daf/competition/ abuse-of-dominance-in-digital-markets-2020.pdf] Accessed 07.02.2021.
} 
is true for the Diem as well. It is collectively admitted that in this case the so called SSNIP (short but significant and non-transitory increase in price) test cannot be used in order to define the markets share. Actually, in those cases, one should take into consideration various parameters of competitions in order to decide on the market power of each company competing in the market, for example the quality of its services, expressed mainly via innovation or protection of privacy. To this end, in order to eliminate the disadvantages of the SSNIP test, courts and the Commission suggests the employment of another test; the SSNDQ (short but significant and non-transitory decrease in quality) test ${ }^{19}$, which is mainly based on the 'decrease in quality parameter' rather than the price.

The actual question concerns whether those tests can be applied to the blockchain market which appears to have completely different traits compared even with multi-sided digital markets ${ }^{20}$. The answer to this question shall be negative. As an initial remark, one should keep in mind the decentralized nature of blockchain organizations which do not even constitute legal units. Indeed, the existence of blockchain doubts the notion of the 'dominant position' itself as it is perceived today ${ }^{21}$. Attached to that, one reasonable question could be whether it is possible for a non-legal entity to possess a dominant position or whether it is possible to have a 'monopoly without a monopolist'. ${ }^{22}$

As preliminary remark, before even attempting to answer the question, one should make an actual distinction concerning the product scope of the market that is going to be defined. Blockchain technology, as explained, presents multiple applications in business life nowadays and its potential uses still remain unknown. Therefore, by mentioning to the blockchain market, one can refer either to the blockchain technology as infrastructure or to the actual operators of the software (especially, persons 'running the blockchain'). For example, on infrastructure level, the discussion may concern Ethereum, or even a 'brand new' blockchain that was programmed for a company (for example, in the course of an initial coin offering

19 Patakyova MT., Competition Law in Digital Era-How to define the relevant market?, 2020, pp. 175, [https:// eman-conference.org/wp-content/uploads/2020/10/EMAN.2020.171.pdf] Accessed 07.02.2021.

20 Stylianou K. and Carter N., The Size of the Crypto Economy; Calculating Market Shares of Cryptoassets, exchanges and Mining Pools, Journal of Competition Law and Economics, Vol. 16, No. 4, 2020, pp. 516 (511-551).

${ }_{21}$ Schrepel T., Is Blockchain the death of Antitrust?, Georgetown Law Technology Review, Vol. 281, No. 3, 2019, pp. 302.

22 Ibid; 4. Huberman G., Leshno J. and Moallemi C., Monopoly Without a Monopolist: An Economic Analysis of the Bitcoin payment System 2, 2017, [https://papers.ssrn.com/sol3/papers.cfm?abstract_ id $=3025604]$ Accessed 07.02.2021. 
$\left.-\mathrm{ICO}^{23}\right)$. In contrast, on the operator level, there is very often companies behind the respective blockchain (again, for example the issuer) even if this entity relies on an established blockchain infrastructure. This is exactly the case of Facebook company with the Diem coin.

The aforementioned theoretical distinction is nothing new for the legal thinking; It can be seen just like the issues arising from the Internet was seen when it had been very first invented. For the interpreter one thing is crucial to answer: 'are we talking about the infrastructure, or about the respective website?'.

\section{The notion of 'undertaking'}

In order for the reader to answer this question, they have to go through the analysis of another essential term: the notion of 'firm' adapted to the requirements of the blockchain technology in competition law. In the traditional doctrine, the enterprise is the smallest economic unit, in which free competition law can be applied. The fact that the introduction of the blockchain complicates the boundaries of the company and makes its traditional definition redundant has given rise to a number of theoretical views with a view to redefining it. ${ }^{24}$ Initiating from the classic Ronald Coase's theory of transaction costs as the most contributing factor to the more modern 'theory of granularity' introduced by Schrepel one thing is to be guaranteed; the issue still remains unsolved.

According to this latest theory, there is a narrow 'nucleus' among users of the same blockchain, which can define and control the entire structure of it, therefore bear the sole liability. This control is identified on the basis of various quantitative criteria, such as the technical capacity, the capacity to interfere with the blockchain economic value or the capacity to influence the blockchain norms. ${ }^{25}$ However, even Schrepel's well-structured theory presents gaps to the extent that the concept of undertaking as an entity engaged in economic activity within a structured market is unfortunately lost. Users of blockchain can be natural persons with no involvement into the business market. The narrow 'nucleus' may consist of the sum of those people that cannot constitute in any case legal entities.

23 For definition, see" 7. What is an Initial Coin Offering, available at: [https://corporatefinanceinstitute. com/resources/knowledge/trading-investing/initial-coin-offering-ico/] Accessed 07.02.2021; 'An initial coin offering (ICO) is a type of capital-raising activity in the cryptocurrency and blockchain environment. (...) The main idea of ICOs is leveraging the decentralized systems of blockchain technology in capital-raising activities that will align the interests of various stakeholders.'

24 Schrepel T., The Theory of Granularity, 2020, pp. 14, [https://papers.ssrn.com/sol3/papers.cfm?abstract_id=3519032] Accessed 08.02.2021.

25 Schrepel T., ibid, 46. 
Of course, the adoption of the 'theory of granularity' challenges the interpreter who will give in to it to face significant evidentiary difficulties immediately afterwards. These mainly focus on the proof that a blockchain user actually belongs to the 'nucleus of a blockchain' on the basis of the above criteria. Could in the decentralized ecosystem of the blockchain, however, still be expected a centralized classical dominant undertaking, which controls the market in one of the traditional and prescribed ways? According to the author, something like that would not be possible for typical permissionless blockchain. If this were accepted, it would probably jeopardize the whole antitrust legal system and result in the impunity of the responsible ones for stopping the prohibited conduct. Therefore, to the question of whether there can be a monopoly without a monopolist, the answer inevitably ends up being positive. This is partially confirmed through the wording of the MiCa Regulation (see below). Naturally, there is an exception and this theoretical structure can easily be applied in permissionless blockchains that are organized in a different way; especially within those ecosystems only few people have the right to write the code and actually run the blockchain. In similar situations, this is deemed applicable. Nonetheless, such ecosystems are far from being the rule.

Secondly, even taken for granted that the answer to the previous question would be positive, it is a real fact that blockchain and non-blockchain institutions are in a thorough competition with one another. In this framework, every time a definition is going to take place the market will be defined rather broad, excluding per se the possibility of diagnosing dominance of one actor. For example, that is the case if one considers the market for online payments, in which companies, such as PayPal or VISA payments, are also major players. Blockchain reduces significantly the transaction fees, yet it does not itself constitute a separate market. Only under the scenario that one could argue that there is a separate market for infrastructure, there might be an argument for the inclusion of blockchain technology in it. Namely, to the extent that mining cryptocurrencies and verifying transactions are also subject to fees, just like the normal payments, the existence of a broader market cannot be doubted. However, even then, this theory overlooks the various functions of blockchain and focuses only one; the use as a payment system.

\section{Market definition; different aspects}

\section{First theory}

Despite the aforementioned theoretical obstacles, researchers are still struggling to find those necessary thresholds so that a definition of relevant market is still being viable. To this end, the available suggestions vary. The first theory suggests that each blockchain establishes a separate market in which all users enjoy domi- 
nance and are co-responsible for probable abuses ${ }^{26}$. This definition of the relevant market, according to which each user can suddenly be found liable and therefore be confronted with fines by competition authorities, would probably create a deterrent incentive for the use of the blockchain. In any event, it could only be described as an insurmountable structural flaw in the author's opinion. The notion of dominant position requires the existence or even the possibility of existence of other players in the market, probably with smaller market shares. If each user holds in fact a dominant position, the definition of a relevant market would be in vain, since each user would have a monopoly on that market and would be pleased with it. In this context, there would be no room for anti-competitive practices, since it would be absurd for a monopoly to wish to harm itself. Supposedly that Diem constituted a relevant market itself, then all approved users would be liable for anticompetitive practices, despite the sole fact that Facebook holds the largest number of Diem dollars...

\section{Second theory}

A second theory uses as a benchmark the number of users in the blockchain. In this respect, all the blockchain systems constitute a single market in which those most popular among users also hold a dominant position. ${ }^{27}$ This view has an important advantage in terms of economic analysis when examining market power compared to the previous one, namely the inclusion of so-called 'token effects' created by bringing more users into a blockchain (similar to "networks effects" on digital markets). If try to apply this theory to the Diem case, then a permissioned blockchain cryptocurrency could never hold power and therefore a dominant position in the relevant markets (taking into account that Bitcoin, Ethereum have obtained far more power).

On the other hand, it has a significant disadvantage: eliminates the different function and nature of the blockchain, its sui generis characteristics, but also the fundamental distinction between public and private blockchain systems. In this context, of course, there could not be any preamble or interchangeability in the various blockchains, while the different purpose of each decentralized system seems to be undervalued. The blockchain 2.0 version allows users to run different forms of software on the decentralized system in order to carry out so-called smart contracts. Clearly, these blockchains, such as Ethereum, respond to different types of users, mainly legal persons and companies, and of course their system carries

\footnotetext{
26 Schrepel T., Is Blockchain the death of Antitrust?, Georgetown Law Technology Review, Vol. 281, No. 3, 2019, pp. 302.

$27 \quad$ Ibid, 303.
} 
out transactions of infinitely greater value. Even if this theory were accepted, all dominant blockchain users would still be held liable for breaches of competition law in the terms of a possession of 'collective dominance', yet even without the appropriate 'economic links' required ${ }^{28}$.

Nevertheless, its application could be reasonable if accepted that firstly the relevant product and geographical market is determined and only once, it is done, it is compared to the number of users. So, here, you do not really ignore the characteristics of each cryptocurrency since they have been taken into account during the first step of the analysis. This may function as a solution if the number or users is the decisive criterion. The prominent disadvantage in this situation concerns mainly the necessity to approach every single case from the other side of the market, namely from the consumer's perspective. Under this theory, this kind of perspective seems to be disregarded. Therefore, this theory is also called into question by the author.

\section{Third theory}

A third view suggests that the power of the blockchain should be measured by the number of transactions executed in the blockchain, the value and the number of blocks ${ }^{29}$.

This opinion also has, like the previous case, the disadvantage that all users are considered to be co-holders of dominant position, which cannot be accepted. Each user would potentially be confronted with high fines from the competition authorities because plainly they made the decision to enter a market. Thus, on the one hand, entering the market of a popular blockchain would automatically result in the responsibility for anticompetitive conduct on the grounds of abuse of dominant position. Under this perspective, a kind of per se abuse of dominance can be established without even an anticompetitive action. On the other hand, users that entered the market before the blockchain gain in popularity and fame will strangely be responsible in the future just for the bare fact that they happened to hold a crypto wallet in the past. Consequently, the high volatility of blockchain prices would strongly affect this parameter and therefore liability of the persons involved into the blockchain. Liability for damages without any anticompetitive conduct at all, to the author's opinion, can barely be perceived nowadays for competition law, even under the most recent form of self-learning algorithms.

\footnotetext{
$28 \quad$ Ibid.

29 Ibid.
} 


\section{Fourth theory}

A fourth theory suggests linking the users of the blockchain to their respective position in the market that they are actually active, namely in another external market ${ }^{30}$. Thus, if a Blockchain has Google and Amazon as its users, it's more likely to be considered dominant in the blockchain market. This view could not be accepted logically, since it makes the power of a blockchain in a market dependent on the power of its users in third independent markets. Apart from the fact that big companies normally invest simultaneously in more blockchains or build their own blockchain system (e.g., Facebook), if their blocks' number is small and only a small volume of transactions are carried out, then even a giant company will not give any real power to the blockchain. It should not be forgotten that in the Blockchain apart from the giant companies there are also other users who are put at risk by the mere fact that a large company has invested in the same blockchain as them. This would also weaken legal certainty in the blockchain ecosystem. Only exception, as also above mentioned, is this of a permissionless blockchain which is organized in a different way, allowing only to few users the right to actually exercise control.

Applied in the Diem case, the latter theory could function as a solution, as Facebook is a dominant undertaking in the advertising market. This could potentially limit its power and lead to its liability for potential abuses. However, other users are likely to have obtained a wallet and be co-responsible with Facebook, so it would end up being unfair for the majority of users with no market power. For the limitation of the liability in this case, the 'theory of granularity' may be extensively used. Facebook can be considered as the profound 'nucleus' of the blockchain, yet its role will not limit in the sole participation in the blockchain. One should always keep in mind that the whole Diem infrastructure was inspired and created by the Facebook group of companies, this would respectively result in a narrower relation between the two, maybe with the form of the prior formation of Diem's protocol or with the possession of administrative rights.

\section{Fifth theory}

Another theory supports the definition of the blockchain market according to the consensus mechanism or the mode of governance. ${ }^{31}$ This leads to two markets, the public market and the purchase of the private blockchain. However, the mere differentiation in the way the blockchain operates could not ensure that the sup-

\footnotetext{
$30 \quad$ Ibid.

$31 \quad$ Ibid, 304.
} 
plies of the blockchain, also in view of smart contracts, are not really similar and therefore interchangeable in a common market. The bare fact that Diem functions as a permissioned blockchain cannot exclude the possibility that it is in thorough competition with Bitcoin, for example. As a result, this hypothesis cannot be accepted.

\section{Sixth theory}

Finally, the sixth theoretical view, and probably the most prevalent one, supports the definition of the market based on the available software and products provided by each blockchain. ${ }^{32}$ Therefore, on this basis, the various forms of the Blockchain and the nature of the so-called smart contracts will be used as thresholds for the diagnosis of market power. To this end, Blockchain 1.0 will not be able to be in the same market with Blockchain 2.0. This opinion sounds adequate in the sense that it can bear a common market with blockchain and non-blockchain activities. However, insisting on the definition of the market on the basis of a single decisive criterion can only show the disadvantages of unilateralism and that can be the basis of type I or II errors during its application. Even within the framework of the fully centralized two-sided markets, the Organization for Economic Co-operation and Development (OECD) uses plenty of factors determining the existence of dominance and does not plainly insist on the one criterion or the other ${ }^{33}$. Nevertheless, whenever the discussion comes into the nature of 'smart contracts', one should consider which are actually those elements to evaluate the power between blockchains using the same software applications ${ }^{34}$. In the Case of Diem, it enables the interaction of currencies that are not using blockchain application, such as normal fiat currencies.

\section{Holistic approach}

According to the author's view, as long as markets are moving towards decentralization and digitization, there can be no exclusive formula which is satisfied on every market. The overall analysis should be multifactorial, taking into account all economic data available in each case. The nature of the transactions and smart contracts in itself leads to a form-based approach, which may result in an excessive expansion of the relevant market and thus impunity for infringements of com-

\footnotetext{
$32 \quad$ Ibid, 304.

33 OECD, Abuse of Dominance in Digital Markets, 2020, [http://www.oecd.org/daf/competition/ abuse-of-dominance-in-digital-markets-2020.pdf] Accessed 07.02.2021.

34 Schrepel T., Is Blockchain the death of Antitrust?, Georgetown Law Technology Review, Vol. 281, No. 3, 2019 , pp. 305.
} 
petition law within the blockchain. Since market shares cannot be used strictly unlike all the other markets, it may be possible to establish a correlation index between the number of users in the blockchain, the volume and value of transactions and the various software that may run in the framework of the same blockchain. Therefore, a blockchain may involve several relevant markets, which will in future expand and make their existence more apparent to the competition authorities. Which will be the decisive factor in each case, depends on the characteristics of each new sub-market.

Another factor to be taken into account in determining a dominant position is the blockchain's own revenue from trading through its system. Decentralization as such does not imply that miners or validators do not enjoy any revenue to achieve their work and of course in those cases that the service is carried out 'for free' does not mean that this situation will remain unchanged in the future. As technology evolves, each case brought before the competition authorities is extremely unique. This uniqueness only allows for an in-concreto analysis based on all available data for a certain market. The only difficulty that is easily detected when such a theory of calculation of revenues is being employed is the comparison of the revenues among several blockchains as they are able to take different forms throughout the market.

US jurisprudence ${ }^{35}$ has employed for the definition of the relevant market in the financial sector a good many relevant metrics: total assets, deposits, transactions value/volume, number of users ${ }^{36}$. These metrics shall apply to the cryptocurrencies, as well. Unfortunately, at the level of case-law every time a court was given the opportunity to define the relevant market for blockchains, it normally preferred to reject the appeals and thus, there is no precedence regarding this topic. ${ }^{37}$ However, it is estimated that soon enough it would be binding for an authority or Court to decide on the issue. Blockchain is gaining more and more popularity and users should be aware of the potential dangers they can face with regard to competition law matters.

\subsection{Regulatory initiatives; The MiCa Regulation proposal}

However, Courts are not the only ones responsible to apply antitrust legislation. The aforementioned analysis can also be carried out ex ante in the context of the

35 See for example; US v. Phillipsburg National Bank \& Trust, 399 U.S. 350; US v. Philadelphia National Bank, 374 U.S. 321.

36 Stylianou K. et al, ibid, 520.

37 Decision Gallagher v. The Bitcoin Foundation (CV 185892) (28.06.2019)/ Decision Leibowitz et al. v. iFines Inc (06.10.2019). 
European Union merger control. Initiating from this thought, it comes as no surprise if international and European competition authorities decide to regulate the market before the introduction of a new blockchain from a competition law aspect. Precautionary policy is considered to be more efficient than ex post measures against an established and unknown situation. The first step is already done with the proposal for a regulation of the European Parliament and the Council on Markets in crypto-assets (MiCa proposal), ${ }^{38}$ which in fact seems to impose clear and well specified rules to ensure legal certainty on the sector. ${ }^{39}$

One of the most interesting aspects that concern the object of this study is the introduction by the MiCa Regulation Proposal of an indirect prohibition on the issuance of stablecoins, ${ }^{40}$ such as Diem, within the European Union, since the conditions require now the prior authorization by a credit or e-money institution. ${ }^{41}$ The thresholds for that are so high that it would not be profitable for any stablecoin organizations to comply with them. That naturally prevents Diem expansion, yet it prevents the expansion of any stablecoin unjustifiably, as well.

Under Title VI of the MiCa Regulation 'Prevention of Market Abuse involving crypto-assets' (articles 76-80), there are some predictions concerning the prevention of market abuse practices. One can easily understand that this chapter indirectly recalls article 102 TFEU ('abuse of market power') and introduces somehow antitrust legislation. The first remark that partially confirms the theory that there can be a monopoly without a monopolist is the usage of the word 'persons' instead of the term 'undertakings' in the wording of the law. ${ }^{42}$ It is a silent recognition that there are steps towards a new reality that is going to be introduced through the usage of this technology. One step further, that could potentially lead to the conclusion that antitrust legislation has started to abstain from the notion of 'undertaking' as detected in case-law and practice until recently. Actually, it consists one of the most major changes to the extent that it constitutes an indirect confession that non-legal entities can bear the responsibility for illegal, exploitative (as well as anticompetitive) conduct.

38 Proposal for a REGULATION OF THE EUROPEAN PARLIAMENT AND OF THE COUNCIL on Markets in Crypto-assets, and amending Directive (EU) 2019/1937 (COM/2020/593 final.

39 Hansen P., New Crypto Rules in the European Union-Gateway for Mass Adoption or Excessive Regulation?, 2021, [https://law.stanford.edu/2021/01/12/new-crypto-rules-in-the-eu-gateway-for-massadoption-or-excessive-regulation/] Accessed 08.02.2021.

40 A stablecoin is a new class of cryptocurrencies that attempts to offer price stability and are backed by a reserve asset (definition available at: Investopedia.com). The most famous stablecoin is Tether.

41 Hansen P., op.cit., note 39.

42 Of course, if the coins are offered in a permissioned blockchain, there might well be a monopolist (or at least a company/entity behind everything). 
It seems that the trend towards overregulation of the market is about to prevail, and the prior regime of total indifference of regulatory authorities tends to move towards risky and excessive legislative initiatives. In the author's view, one should pay attention not to reach to the other side with the overregulation of the market. Blockchain technology can surely bear challenges for the authorities, yet the possibility of development and improvement of the technology must remain wide open. Regulatory intervention should not end up being an expression of strength on behalf of the institutions for the simple reason that stablecoins and their blockchain mechanism can also bear efficiencies in the market (e.g., reduction of transaction fees, elimination of search costs and data protection). Too much regulation jeopardizes and eliminates innovation causing market stability and eventually consumer harm.

\subsection{Blockchain as data protector vs. Facebook business plan}

Indeed, the application of 102 TFEU will bring the issue of the definition of relevant market for blockchains in the foreground. It is a fact arising from the Commission's recent practice that the modern currency, which businesses are struggling to obtain in the information era, is 'data'. Business giants, like Facebook, use user data on the social media platform to provide information to advertising businesses, acting as a channel between two markets (also known under the term 'two-sided platform').

As mentioned, Diem was released as a permissioned blockchain with the prospect of being permissionless within an unspecified time period. This announcement caused panic internationally in the competition committees and it caused legislative action (see above MiCa Regulation). Indeed, since it has been implemented, one can see many risks of reporting on Facebook of extremely important economic data by users. Facebook will manage to obtain a really wide portfolio of data and become a monopolist in the online advertising market, namely without even competitors.

First of all, there is a possibility of tying Facebook and Novi services in the sense that only users with a personal account can acquire a wallet and therefore access to the cryptocurrency. ${ }^{43}$ Secondly, there can be cases of misuse of power in the sense of 'refusal to deal' or 'exclusive dealing'. Initiating from this thought, it should be clearly stated whether an online platform be considered as an 'essential facility', according to the IMS Health or Magill judgement. ${ }^{44}$ At present, such a possibil-

\footnotetext{
$43 \quad$ Schrepel T., op. cit, note 7, p. 165.

44 Ibid, 166.
} 
ity can be strongly denied, yet one cannot easily predict the growth of Facebook's database after the introduction of Diem. It can be highly possible that Facebook will function as an essential facility for the modern advertising markets, especially if all potential competition is vanished.

This scenario is probably not at all desirable for regulatory authorities. It is evident that Facebook intends to expand its existing economic eco-system and hide behind modern technologies, such as the cryptos. Consequently, Facebook would be the one and only solution for every business that dreams of accessing the online market and advertise its products through online channels. Secondly, the database concentrated by Facebook is estimated to be that big that is going actually to function as market entry barrier for every company which potentially desire to exercise competition to Facebook for the market.

However, the regulatory treatment should be mediocre instead of completely neglecting the blockchain technology. Despite the potential anticompetitive threats that flow from Facebook's undoubted dominant position at present, blockchain technology -mainly permissionless blockchains- can, generally speaking, when not used by companies with too much power in the international markets, function as a solution to the collection of data problem. In fact, the transparent and encrypted system is the ideal way for users to keep their data safe and reduce the data collected through online platforms e.g., Facebook. It is natural that if those companies start losing a major part of their data due to the blockchains, the quality of their services as "data providers" will decrease. Competition authorities, nowadays, have ended up being the protector of consumer's data as an aspect of consumers' welfare. Blockchain technology, if widely used can as means to solve many problems that competition law itself cannot properly handle. The concern about Facebook's planning, at the end of the day, has less to do with the blockchain technology as such than with the expansion of its data portfolio. This is something that should sparkle the interest of the competent authorities, as well.

\section{CONCLUSION}

The specific characteristics of the blockchain technology far outweigh the possibilities of the available tools and instruments available to competition authorities throughout the world for effective enforcement of antitrust legislation. As proved, even prior to the introduction of blockchain in the market, there are terms that ought to be reformed'; the notion of 'undertaking', the definition of what is called 'relevant market'. The need for regulatory reforms to be developed and carried out by the various central institutions is essential and urgent. In this context, it has been argued in theory that the possible prevalence of the blockchain endangers the 
whole structure of competition law as positive law in its present form, leaving it essentially unproductive and unjustified. ${ }^{45}$

The author's opinion is that competition law consists of rules designed to regulate the entire market and all sectors of the economy. Their laconic wording is clearly due to the fact that they are open not only to completing, but also to a dynamic interpretation of the terms and notions in question. As an example, already with the introduction of centralized platforms (Amazon, Google etc.), there is a large extension of the existing interpretative tools and competition law has shown in its implementation that it is bound neither by restrictive formalities nor by narrow definitions. The researcher can easily diagnose that all terms are being adapted to a rational of economic analysis from which they used to abstain and move towards a more form-based approach.

The latter also demonstrates the adaptability of competition law to market circumstances, just like civil law follows the complexity of human relations and transactions. The market as such is not a sum of static formulated relationships, but it is a living organization which constantly presents new forms of relations to help simplify business norms. If competition law was designed to regulate the market solely in a concrete period of time, then it would be vulnerable to self-extinction whenever a new situation jeopardized its validity. The conclusion is that the introduction of more specialized regulatory frameworks, the development itself, does not result neither in the extinction of competition law nor in the loss of its basic objectives. On the contrary, it seems to introduce a new phase of legal analysis, which will follow the digitalization of the available media.

As far as the objectives are concerned, the decentralization of markets does not itself guarantee the preservation of market competition or the maximization of consumer welfare, so that one could reasonably argue that there is no more need for antitrust law. The uselessness of intermediaries and the horizontalization of relations do not at all exclude the possibility of the continuation of anti-competitive practices or the exploitation of monopolistic positions. Competition law is the only one responsible to provide for the tools to safeguard market conditions, indifferent if there does exist a traditional "trustee" or not. ${ }^{46}$ The word "antitrust" can easily be considered another cliché and remain in history books, just like so many other terms (e.g., the word 'quarantine' which used to be useless until recently).

45 Schrepel T., Is Blockchain the death of Antitrust?, Georgetown Law Technology Review, Vol. 281, No. 3, 2019, pp. 334-8.

46 Collins W.D, Trusts and the Origins of Antitrust Legislation, Fordham Law Review, Vol. 81, 2013, pp. 2279. I Schrepel T., Is Blockchain the death of Antitrust?, Georgetown Law Technology Review, Vol. 281, No. 3, 2019, pp. 337. 
The truth is that competition law rules need reform and dynamic interpretation in order to maintain their power and legitimacy.

As concluding remark: why is this considered as so necessary that one actually spoke of the 'death of antitrust' rather than the 'birth of the ex-ante regulation/ control of software' run over blockchain systems? This initiative would certainly enhance knowledge on the existing technology and favorize the understanding of the nature of blockchain markets. Competition comes as the appropriate element to supplement those cases that could not objectively be predicted by the responsible authorities. As market develops and changes, so does competition law throughout time.

It is a fact that the blockchain market has come up with a number of absurdities, which competition law is now called upon to resolve in order to safeguard the reasons for its establishment. Academic dialog is increasing and several theories have already been put forward to define it. The author hopes to have contributed to this academic exchange through this study.

Although the usage of examples cannot be considered a safe channel for concluding, the Facebook example provided the appropriate stimulus for dealing with a field of law that previously belonged to the sphere of science fiction. Large companies have already started to operate in the market and the first challenges for competition law have already begun to form. As markets tend to be more decentralized and obtain different characteristics, market leverage is likely to take various forms and expand through unchanneled ways. The conclusion is that no matter how rapid technology develops and market condition change, regulation and antitrust should not stop, but serve the legitimate objectives for the sake of which they were initially issued and which remain unchanged... throughout time.

\section{REFERENCES}

\section{BOOKS AND ARTICLES}

1. Arranguez-Diaz P., A New Opportunity for digital Competition: Facebook, Libra and Antitrust, Stetson Law Review Vol. 50, 2020, pp. 199.

2. Collins W.D, Trusts and the Origins of Antitrust Legislation, Fordham Law Review, Vol. 81, 2013, pp. 2279.

3. Nofer N., Gomber P., Hinz Ol., Schiereck D., Blockchain, Business and Information Systems Engineering, Vol. 59, No. 3, 2017, pp. 183-187.

4. Schrepel T., Libra: A Concentrate of Blockchain Antitrust, Michigan Law review Online, Vol. 118, 2020, pp. 165.

5. Schrepel T., Is Blockchain the death of Antitrust?, Georgetown Law Technology Review, Vol. 281, No. 3, 2019, pp. 337. 
6. Stylianou K. and Carter N., The Size of the Crypto Economy; Calculating Market Shares of Cryptoassets, exchanges and Mining Pools, Journal of Competition Law and Economics, Vol. 16, No. 4, 2020, pp. 511-551.

\section{EU LAW}

1. Treaty of Lisbon amending the Treaty on European Union and the Treaty establishing the European Community [2007] OJ C306/01.

2. Proposal for a REGULATION OF THE EUROPEAN PARLIAMENT AND OF THE COUNCIL on Markets in Crypto-assets, and amending Directive (EU) 2019/1937 (COM/2020/593 final)

\section{WEBSITE REFERENCES}

1. Beyoud and White, Facebook's Libra Currency gets European Union Antitrust Scrutiny, 2019, [https://www.bloomberg.com/news/articles/2019-08-20/facebook-s-libra-currencygets-european-union-antitrust-scrutiny] Accessed 08.02.2021.

2. Diem White Paper, [https://www.diem.com/en-us/wp-content/uploads/2019/06/LibraWhitePaper_en_US.pdf] Accessed 07.02.2021.

3. Hansen P., New Crypto Rules in the European Union-Gateway for Mass Adoption or Excessive Regulation?, 2021, [https://law.stanford.edu/2021/01/12/new-crypto-rules-in-the-eu-gateway-for-mass-adoption-or-excessive-regulation/] Accessed 08.02.2021.

4. Huberman G., Leshno J. and Moallemi C., Monopoly Without a Monopolist: An Economic Analysis of the Bitcoin payment System 2, 2017, [https://papers.ssrn.com/sol3/papers. cfm?abstract_id=3025604] Accessed 07.02.2021.

5. OECD, Abuse of Dominance in Digital Markets, 2020, [http://www.oecd.org/daf/competition/abuse-of-dominance-in-digital-markets-2020.pdf] Accessed 07.02.2021.

6. Patakyova MT., Competition Law in Digital Era-How to define the relevant market?, 2020, [https://eman-conference.org/wp-content/uploads/2020/10/EMAN.2020.171.pdf] Accessed 07.02.2021.

7. Schrepel T., The Theory of Granularity, 2020, [https://papers.ssrn.com/sol3/papers. cfm?abstract_id=3519032] Accessed 08.02.2021.

8. What is an Initial Coin Offering, available at: [https://corporatefinanceinstitute.com/resources/knowledge/trading-investing/initial-coin-offering-ico/] Accessed 07.02.2021.

9. Yaga D., Mell P., Roby N. and Scarfone K., Blockchain technology overview, 2018 [https:// arxiv.org/ftp/arxiv/papers/1906/1906.11078.pdf] Accessed 30.06.2021. 